\title{
Análise do ambiente escolar: Escola Estadual Doutor Liberato Salzano Vieira da Cunha (Cachoeira do Sul, RS)
}

\author{
School Environment Analysis: Doutor Liberato Salzano Vieira da Cunha State School \\ (Cachoeira do Sul, RS, Brazil)
}

Ariane Brum Rodrigues ${ }^{1}$, Andreza Micaela Oliveira Nunes ${ }^{2}$, Gustavo Streck Severo ${ }^{3}$ e Bárbara Maria Giaccom-Ribeiro ${ }^{4}$

${ }^{1}$ Universidade Federal de Santa Maria, Campus Cachoeira do Sul, Coordenadoria Acadêmica, Curso de Arquitetura e Urbanismo, Cachoeira do Sul, RS, Brasil arianebrumrodrigues@hotmail.com

${ }^{2,3,4}$ Universidade Federal de Santa Maria, Campus Cachoeira do Sul, Curso de Arquitetura e Urbanismo, Cachoeira do Sul, RS, Brasil

andrezanunes_trabalho@hotmail.com; gustavo.streck.severo@gmail.com; barbara.giaccom@ufsm.br

\section{Resumo}

A disciplina de Projeto V do Curso de Arquitetura e Urbanismo da Universidade Federal de Santa Maria, Campus Cachoeira do Sul, contemplou, no primeiro semestre de 2018, o projeto de um equipamento urbano de educação. O anteprojeto arquitetônico desenvolvido pelos discentes é anteposto pela análise crítica de projetos arquitetônicos de instituições de ensino. Realizou-se, para tanto, visita técnica à Escola Estadual Doutor Liberato Salzano Vieira da Cunha, localizada na cidade de Cachoeira do Sul- RS. Essa visita viabilizou o levantamento de dados e o entendimento da influência do espaço construído no cotidiano dos usuários. A análise levou em consideração, sobretudo, os seguintes aspectos: inserção urbana, contexto social e cultural, soluções plástica e volumétrica da edificação, solução dos espaços internos, programa arquitetônico existente e organização de fluxos. A metodologia utilizada para exposição dos resultados ao restante da turma compreendeu, entre outras coisas, a concepção de uma maquete eletrônica que auxiliou no entendimento do espaço e das particularidades arquitetônicas da edificação. O trabalho objetiva, portanto, expor a análise e os resultados obtidos a partir da visita técnica, contextualizar histórica e socialmente a Escola na realidade educacional de Cachoeira do Sul, além de especificar particularidades da metodologia de análise e apresentação.

Palavras-chave: Equipamento educacional; Cachoeira do Sul; Análise espacial tridimensional virtual

\section{Abstract}

The Architectural Design 5 course in the Architecture and Urbanism Undergraduate Program of the Federal University of Santa Maria, Cachoeira do Sul Campus (state of Rio Grande do Sul, Brazil) contemplates, in the first half of 2018, the design of an educational urban equipment. The architectural design developed by the students is preceded by the critical analysis of architectural projects of educational institutions. For this purpose, technical visits were made to the "Doutor Liberato Salzano Vieira da Cunha" State School, located in the city of Cachoeira do Sul. The technical visit enabled data collection and the understanding of the influence of the built space in the users' daily life. The analysis particularly considered the following aspects: urban insertion, social and cultural contexts, the building's plastic and volumetric solutions, internal spaces solution, existing architectural program and flow organization. The methodology used for exposing the results to the other classmates included, besides ancillary resources, the design of an electronic model that helps understanding the space and the architectural particularities of the building. The objective of this work is to present the analysis and the results obtained from the technical visit, to contextualize the School in the educational reality of Cachoeira do Sul, in addition to specifying particularities of the methodology of analysis and presentation.

Keywords: Educational equipment; Cachoeira do Sul; Virtual three-dimensional spatial analysis 


\section{Introdução}

O Curso de Arquitetura e Urbanismo da Universidade Federal de Santa Maria (UFSM), Campus Cachoeira do Sul, objetiva "formar profissionais arquitetos e urbanistas flexíveis, inovadores, competentes, conscientes, cidadãos e que compreendam as necessidades humanas em suas dimensões culturais, propondo e executando soluções arquitetônicas e urbanísticas ecologicamente adequadas e comprometidas com o equilíbrio entre os interesses individuais e coletivos”.

Com esta preocupação, a disciplina de Projeto V, oferecida no primeiro semestre de 2018, propôs a concepção projetual de equipamento urbano de educação, com vistas a responder às necessidades e condicionantes com soluções conceituais, formais, funcionais e técnicas, que qualificassem o contexto físico, ambiental, social e cultural. Os estudantes foram levados a refletir criticamente e conceber objeto arquitetônico no âmbito do entorno e bairro, percebendo os elementos da paisagem como constituintes da situação de projeto.

Tendo como temática principal a arquitetura escolar e suas influências dentro do contexto urbano, a disciplina de Projeto V propôs um primeiro contato com as questões específicas do tema por meio da realização de análises de equipamentos educacionais, tanto de exemplos nacionais, quanto internacionais. Para Teixeira (1960), o espaço escolar, como nenhum outro elemento, é tão fundamental, no complexo da situação educacional, depois do professor, como o prédio e suas instalações. Sophia (2007) defende que fazer arquitetura é entender um problema, refletir, planejar, muito mais que desenhar.

A análise de casos possibilita o entendimento dos espaços internos, programa, fluxos, dinâmica escolar e a relação com o entorno imediato, e desta forma, permite compreender a influência do ambiente na aprendizagem. Segundo Gil (2002), o estudo de caso é caracterizado pelo estudo profundo e exaustivo de um ou de poucos objetos, de maneira a permitir o seu conhecimento amplo e detalhado. O estudo de caso é encarado como o delineamento mais adequado para a investigação de um fenômeno contemporâneo dentro de seu contexto real, onde os limites entre o fenômeno e o contexto não são claramente percebidos (YIN, 2001).

No contexto nacional, foi analisada a Escola Estadual Doutor Liberato Salzano Vieira da Cunha, localizada no município de Cachoeira do sul. A escolha possibilitou a vivência espacial, associada ao contexto local. A possibilidade de realizar visitas técnicas pessoalmente esse estudo de caso permitiu entender as estratégias espaciais e formais utilizadas para a dinâmica educacional. A coleta de dados in situ, associada à pesquisa documental, forneceu dados para concepção de uma maquete eletrônica, que auxiliou na compreensão dos fluxos do projeto, bem como o entendimento do espaço e das particularidades arquitetônicas da edificação.

O presente trabalho tem como objetivo expor as análises e as discussões dos resultados obtidos a partir da visita técnica, contextualizar histórica e socialmente a Escola Doutor Liberato Salzano Vieira da Cunha na realidade educacional do município de Cachoeira do Sul. Outro objetivo é especificar particularidades da metodologia de análise e apresentação. 


\section{Fundamentação Teórica}

Os pormenores explorados nesta pesquisa foram norteados pelo livro "Conceitos e Tendências da Arquitetura Escolar", de Doris Kowaltowski. A autora explora, de maneira didática, aspectos espaciais e conceituais que auxiliam no desenvolvimento escolar.

A leitura conduz uma reflexão acerca da responsabilidade social do arquiteto e sua contribuição para com o equipamento urbano educacional. A padronização do ensino retrata, em muitos casos, uma unificação espacial que limita os usuários a um comportamento padrão. A configuração hierarquizada - valorização da autoridade - fez parte do ensino brasileiro por décadas e sofre, atualmente, adaptações compatíveis aos novos métodos de ensino. O propósito de garantir um bom currículo aos discentes faz com que, por vezes, os educadores não relacionem o espaço físico ao conhecimento, e é nesta conjuntura que $\mathrm{o}$ arquiteto se insere.

Para McDonald (1996), "o currículo de uma escola deve influenciar o projeto dos ambientes". Neste âmbito é viável determinar que cada metodologia pedagógica exige um projeto específico, e este deve atender às necessidades de forma coerente, seja na dimensão dos espaços, seja na funcionalidade, ou infraestrutura, distribuição de fluxos, dentre outros aspectos.

As salas de aula são exploradas e analisadas exaustivamente por Kowaltowski (2012), que enfatiza sua importância no processo cognitivo. Esta autora sugere configurações que rompam com padrões dos modelos espaciais antigos - embora utilizados até hoje - e atenta para a relevância da flexibilidade do mobiliário, de modo a compor, num mesmo espaço, novas dinâmicas de aula, como, por exemplo, formar círculos ou agrupar mesas, dentre outras organizações que se adequem ao modelo de ensino desejado.

Além desses tópicos, são abordados parâmetros como a relação entre espaços internos e externos, configuração de pátios e criação de recantos para o usuário apropriar-se de maneiras distintas. Kowaltowski (2012) contempla a relação dos espaços verdes e o desenvolvimento sensorial a partir de materialidades aplicadas ao ambiente.

"Há diversos tipos de inteligências por explorar nas escolas, para cada aluno descobrir suas potencialidades, desenvolvendo as mais frágeis e expressando as mais fortes" (KOWALTOWSKI, 2012, p. 186). Para ser realizável o progresso das inteligências múltiplas - musical, corporal, interpessoal, existencial, dentre outras - são imprescindíveis espaços alternativos para além de salas de aula padrão, devendo-se promover, portanto, ambientes distintos destas, como espaços multiuso, de jogos, de leitura, lúdicos, áreas abertas, laboratórios, entre outros cenários importantes para o avanço e diversificação da aprendizagem.

Os condicionantes físicos também devem ser explorados: neste sentido, Kowaltowski (2012) observa questões de como conforto acústico, lumínico e térmico, e orientação espacial influenciam no comportamento e no bem-estar, e devem ser ajustados às necessidades de cada localidade. Tais conceitos e parâmetros nortearam a análise da Escola Estadual Doutor Liberato Salzano Vieira da Cunha, que é apresentada a seguir. 


\section{Apresentação da Escola Estadual Dr. Liberato Salzano Vieira da Cunha}

A Escola Estadual Doutor Liberato Salzano Vieira da Cunha é proveniente do Programa de Expansão e Melhoria do Ensino Médio (PREMEM) originado durante o período da Ditadura Militar (1964-1985), por meio de um acordo com os Estados Unidos da América, objetivando reformular o ensino de $1^{\circ}$ e $2^{\circ}$ graus. Em âmbito nacional, o PREMEM resultou nas escolas polivalentes. Por solicitação do Ministério da Educação, foram elaborados projetos-padrão educacionais que pretendiam uma formação integrada de saberes básicos integrados a práticas profissionalizantes divididas em áreas econômicas: primária (e.g., olericultura, jardinagem, fruticultura, indústria de produtos alimentícios e zootecnia); secundária (e.g., artes gráficas, cerâmica, eletricidade, madeira, metal, mecânica); terciária (e.g., miniempresas, atividades comerciais, bancárias e de escritório, datilografia, habitação e decoração).

Em Cachoeira do Sul, as negociações foram iniciadas em 1971. Em 22 de agosto de 1972, a Lei Municipal nº 1.556 aprovou - segundo o acervo da escola - os termos do convênio a ser celebrado entre o PREMEM e a Prefeitura Municipal de Cachoeira do Sul - à época, conduzida pelo prefeito Honorato de Souza Santos -, autorizando a doação do terreno, localizado na Rua Cel. João Leitão, número 1546, no bairro Barcelos, e dando outras providências.

O projeto arquitetônico foi elaborado pelo escritório Aflalo \& Gasperini Arquitetos e o projeto estrutural, pelo engenheiro José Carlos de Figueiredo Ferraz. A construção do colégio foi iniciada em 1973, pela Construtora Cachoeirense, tendo sido concluída em 1974. Conforme o arquivo da escola, em 14 de novembro 1974 chegaram os primeiros materiais pertinentes a cada setor. O atendimento aos alunos foi iniciado em março de 1975 (Figura 1).

Figura 1 - Imagem da realização de atividades em sala de aula

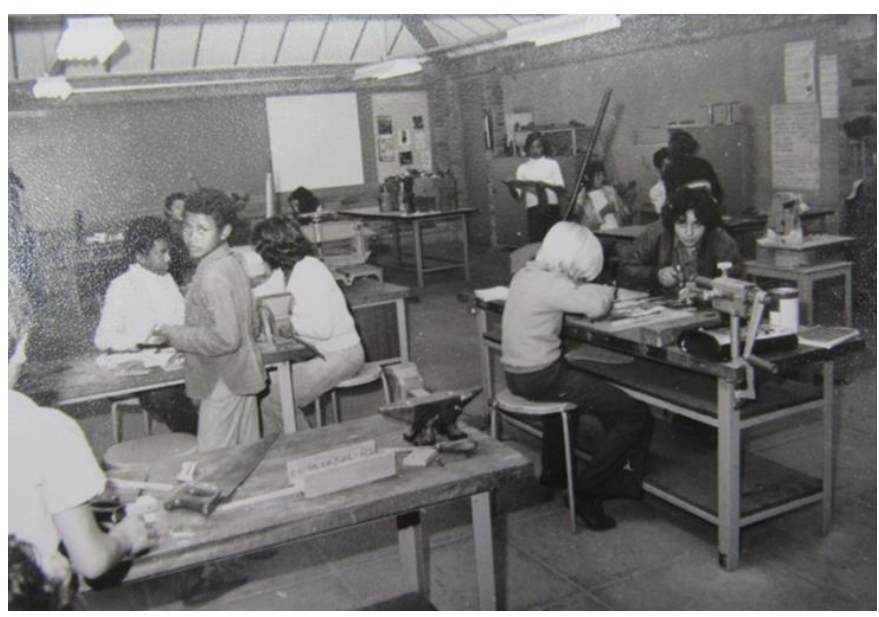

Fonte: Acervo da Escola Doutor Liberato Salzano Vieira da Cunha (2018)

A relação dos primeiros professores, encontrada em arquivos da Escola, revela o ensino de técnicas comerciais, domésticas e industriais, aliado às disciplinas tradicionais. Além disso, registra-se que a autorização para funcionamento foi emitida em 1976, em discordância a outros dados que apontam o início das atividades em 1975. Notabiliza-se que, inicialmente, em 1976, a Escola oferecia turmas de $5^{\mathrm{a}}$ a $8^{\mathrm{a}}$ série. A partir de 1987 , passou a disponibilizar também turmas de $1^{\mathrm{a}}$ a $4^{\mathrm{a}}$ série. Posteriormente, em 1990, a Escola foi ampliada por meio da anexação, à estrutura original, de quatro novas salas de aula.

Ao longo de seus 43 anos de existência, para atender às demandas da comunidade escolar, outras modificações estruturais também foram ocorrendo na edificação. Recentemente, entre outras melhorias, cita-se a implantação de uma quadra 
poliesportiva coberta e a construção de um muro de alvenaria em todo perímetro do terreno. Na atualidade, a escola funciona nos turnos da manhã, tarde e noite, e atende 635 alunos matriculados em turmas de ensino fundamental, ensino médio e EJA (Educação Jovens e Adultos).

\section{Metodologia}

A metodologia aplicada neste trabalho pode ser classificada como exploratória com observação direta. Os dados foram coletados a partir de visita técnica à Escola Estadual de Ensino Fundamental Doutor Liberato Salzano Vieira da Cunha e entrevista com a vice-diretora Simone Martins Franco.

A pesquisa iniciou-se com a análise de mapas, referentes à inserção da escola no bairro, observando aspectos como vias, tipos de pavimentação e sentido de fluxos, que auxiliaram para compreensão do contexto no qual a escola está localizada. Em seguida, foi realizada uma visita técnica ao colégio, que permitiu que fossem feitos a entrevista com a vice-diretora e os levantamentos fotográficos e espaciais que auxiliaram na produção, posteriormente, de uma maquete eletrônica tridimensional.

\section{Resultado e Discussão}

A escola apresenta uma inserção urbana periférica no município de Cachoeira do Sul, em um bairro predominantemente residencial (i.e., Barcelos) (Figura 2). A diversidade urbana em seu entorno imediato, conforme constatado, restringe-se a pequenos estabelecimentos comerciais e de prestação de serviços. O terreno abrange uma quadra inteira, de formato irregular, contabilizando aproximadamente 26.500 metros quadrados de área. A área construída, entretanto, restringe-se a cerca de 3.500 metros quadrados.

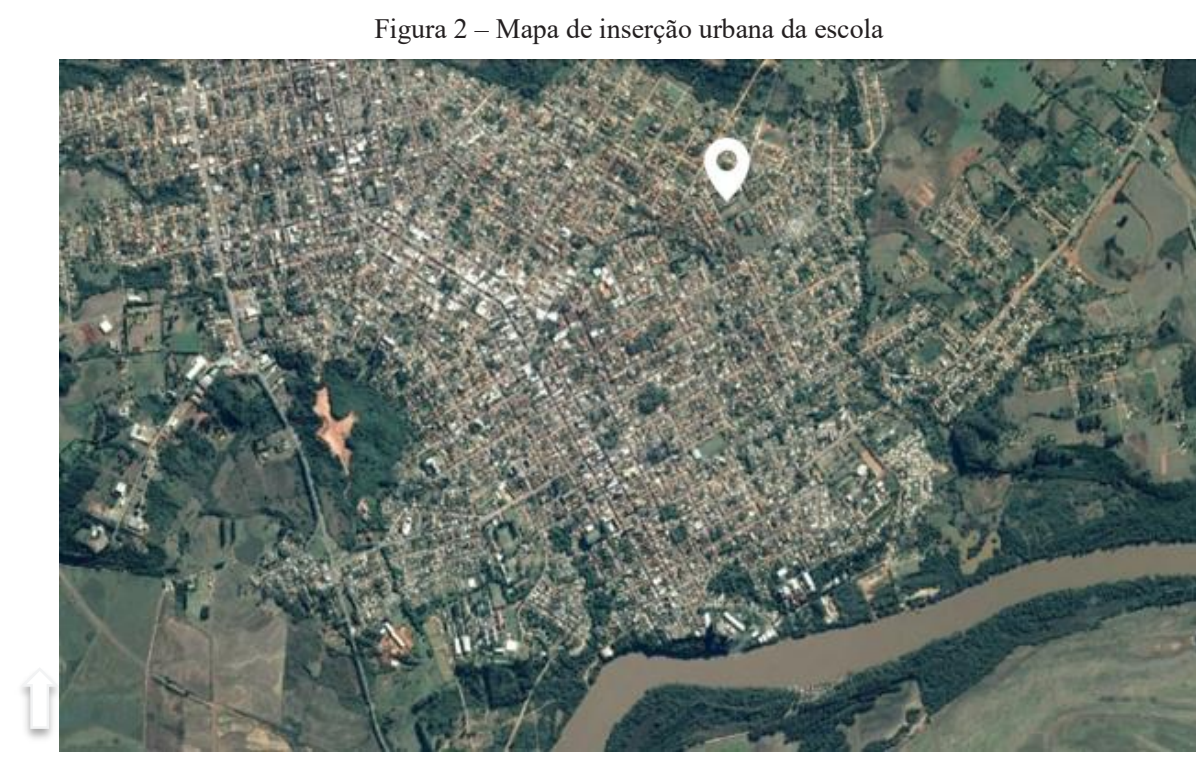

Fonte: autores (2018)

As vias adjacentes caracterizam-se por apresentarem três distintas materialidades: paralelepípedo, na Rua Coronel João Leitão, onde se situa o acesso à Escola, e na Rua Henrique Müller; asfalto, na Rua Ernesto Müller, onde se localiza uma parada de ônibus; "chão batido", ou seja, ausência de pavimentação, na Rua Manoel Santos Pessoa, aos fundos do lote. Constata-se que o fluxo de veículos nos trechos adjacentes à escola - conforme análise nas circunstâncias da visitação - é baixo (Figura 3). Além disso, é perceptível que a materialidade das vias não configura demasiadas hierarquias de tráfego. 
Figura 3 - Mapa de pavimentação das vias adjacentes (paralelepípedo em azul, asfalto em vermelho e "chão batido" em amarelo)

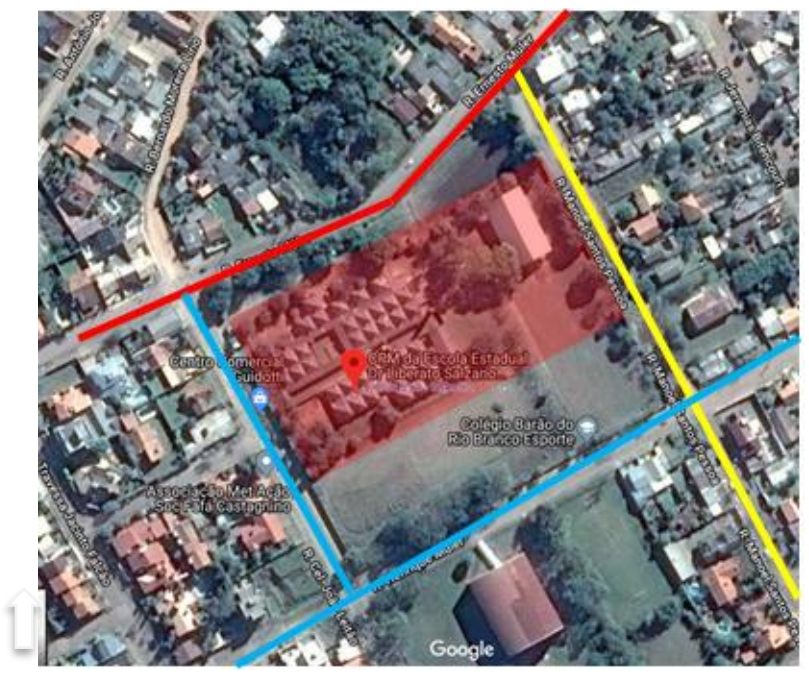

Fonte: autores (março/2018)

Observa-se que a inserção morfológica da escola não proporciona relação com o entorno. O muro de alvenaria que atualmente circunda todo o perímetro do terreno e, portanto, toda a quadra, contribui para desqualificar essa inserção, uma vez que desfavorece a vitalidade das vias adjacentes, resultando em sensação de insegurança. Contribui para isso o fato de a instituição possuir um único ponto de acesso e de os passeios públicos das ruas Ernesto Müller e Manoel Santos Pessoa serem desprovidos de pavimentação, resultando em condições precárias e, por vezes, inseguras de circulação de pedestres.

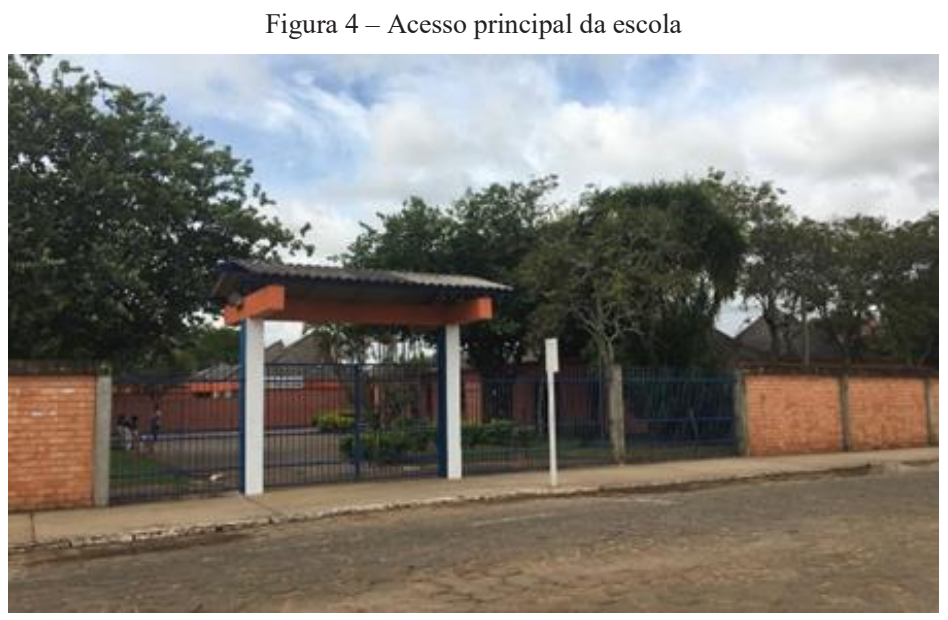

Fonte: autores (março/2018)

Em estilo moderno, a edificação é caracterizada por sua planta baixa organizada a partir de espaços horizontalizados mediados por pátios e corredores abertos. Há racionalidade na segmentação espacial, exemplificada pelo uso de uma modulação rítmica - um quadrado com aproximadamente 7,5 metros de lado - associada a subtrações. A disposição horizontal da edificação permite um melhor aproveitamento do terreno, além de proporcionar melhores condições bioclimáticas ventilação, sobretudo. 
Figura 5 - Planta baixa do projeto arquitetônico original

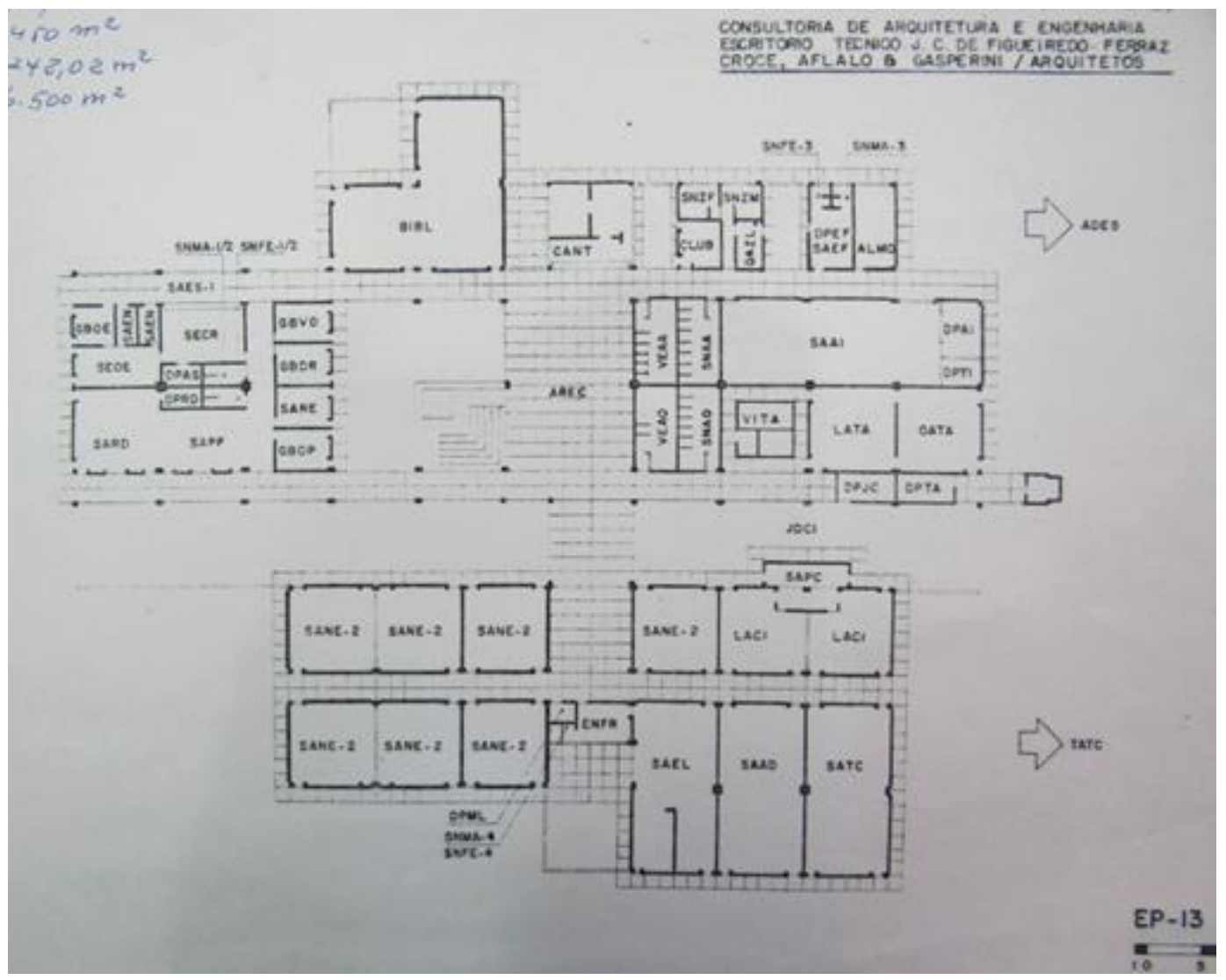

Fonte: Acervo da Escola Doutor Liberato Salzano Vieira da Cunha (2018)

O conjunto apresenta uma volumetria simples, peculiarizada pela forma de sua cobertura: trata-se de telhados compostos por quatro águas, sendo duas delas consideravelmente alongadas para proporcionar aberturas superiores (i.e., sheds). Essas aberturas dispõem de duas faces, orientadas à sudoeste e sudeste. São preenchidas predominantemente por pequenos planos de vidro fixos sustentados por uma estrutura metálica e dispõem, em seu perímetro inferior, de pequenas basculantes inseridas para propiciar a exaustão do ar quente - associando-se à estratégia bioclimática de efeito chaminé. Tais sistemas também objetivam tornar os ambientes permeáveis à iluminação natural.

Observa-se a aplicação de uma estrutura em concreto armado. A vedação é feita em alvenaria, sendo os blocos cerâmicos maciços aparentes. Nota-se, nesse sentido, que os cheios são extremamente preponderantes aos vazios: são poucas e pequenas as fenestrações existentes nas paredes - e, quando existem, encontram-se acima da visão dos usuários. Além disso, constata-se que as vigas de amarração superior das paredes são associadas a calhas, materializadas em concreto.

As características da composição arquitetônica da escola refletem na qualidade dos espaços usufruídos pelos alunos, professores e funcionários. O partido arquitetônico, composto a partir de uma malha regular, mostra-se como um ponto positivo, uma vez que possibilita a adaptação dos ambientes - por exemplo, quando da ampliação ou diminuição de salas de aula através da adição ou subtração de módulos, respectivamente; tais adaptações, inclusive, são procedimentos que foram realizados pela escola em diferentes circunstâncias.

Constata-se, nesse sentido, inúmeras incoerências relativas à utilização atual dos espaços ocasionadas pelas soluções arquitetônicas aplicadas. A principal delas está relacionada ao conforto ambiental. Os sheds, presentes quase que na totalidade dos espaços - devido à falta de manutenção de seus elementos móveis, desconhecimento dos usuários acerca do funcionamento e má orientação solar -, ocasionam o efeito inverso ao que se propõem: os ambientes são quentes, a iluminação 
artificial mostra-se necessária em grande parte do dia e incidência solar direta, em determinados momentos, prejudica o desempenho das atividades escolares. Além disso, a ausência de fenestrações que possibilitem o contato visual dos usuários com o exterior torna os ambientes enclausurados.

Figura 6 - Composição volumétrica proporcionada pela forma da cobertura (a); sheds visualizados do interior de uma sala de aula (b)

(a)

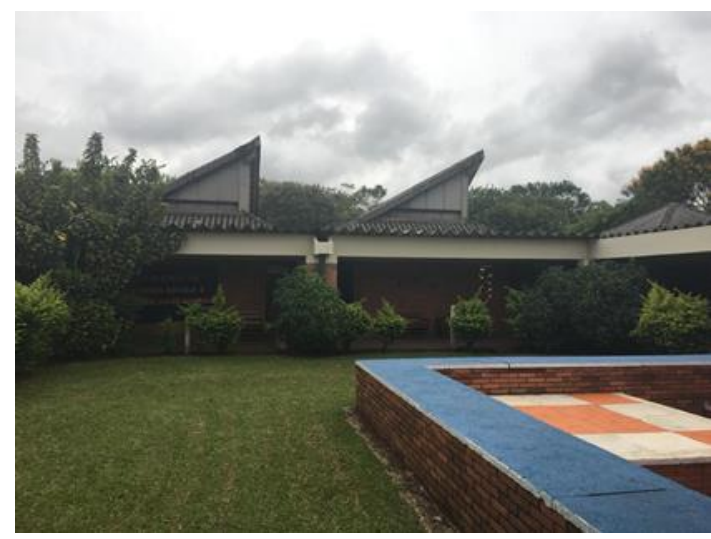

(b)

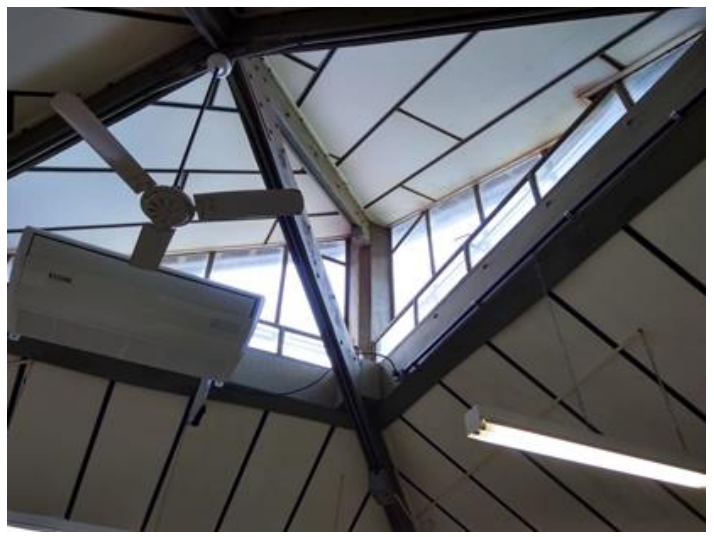

Fonte: autores (março/2018)

Nota-se que as circunstâncias das quais a escola provém e o uso inicial ao qual foi destinado refletem diretamente na qualidade dos espaços. Os ambientes, em sua maioria, não se mostram atrativos à aprendizagem e funcionais aos moldes atuais de ensino. São perceptíveis, entretanto, as tentativas da instituição em qualificar os espaços - tornando-os lúdicos e atrativos aos usuários - mediante aplicação de cores e elementos decorativos, adaptações de mobiliários, articulação das áreas de lazer, tratamento da vegetação, entre outros.
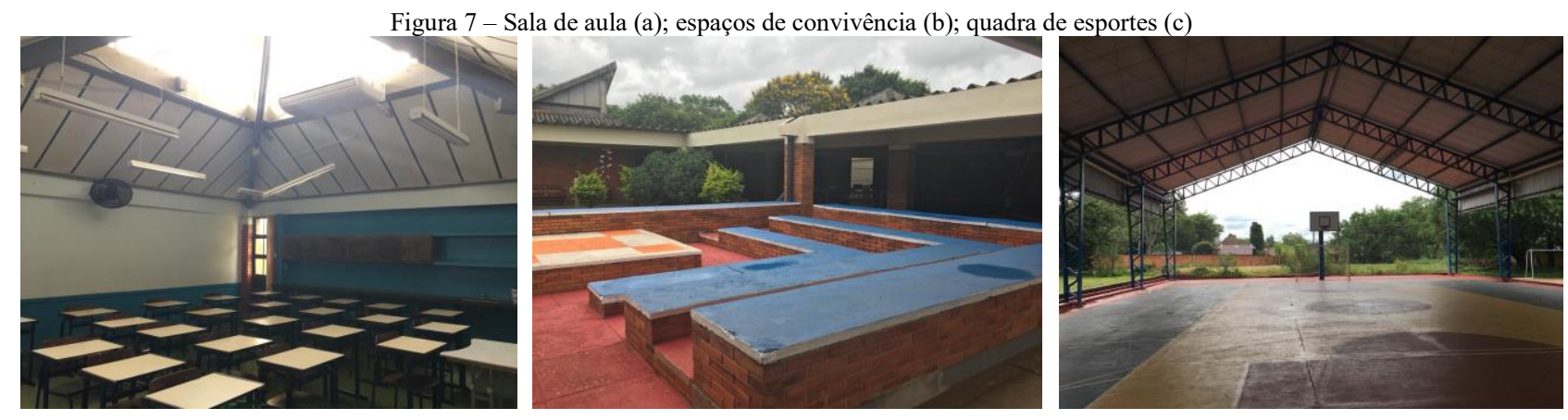

Fonte: autores (março/2018)

A escola apresenta, atualmente, um programa arquitetônico parcialmente concordante às suas necessidades. Conforme os relatos coletados, há carência de determinados espaços, sobretudo de salas de aula. A distribuição do programa existentes, apesar disso, mostra-se racional e funcional, sendo mediada por circulações horizontais - abertas e fechadas. É notória, entretanto, a estruturação dos espaços objetiva controlar os alunos - o que, segundo a vice-diretora, é necessário por questões de segurança. Nota-se, nesse contexto, que a compreensão da distribuição dos espaços, bem como da composição geral da escola, foi facilitada pela produção do modelo tridimensional. 
Figura 8 - Maquete eletrônica tridimensional: distribuição do programa arquitetônico (a); perspectiva da composição volumétrica (b)

(a)

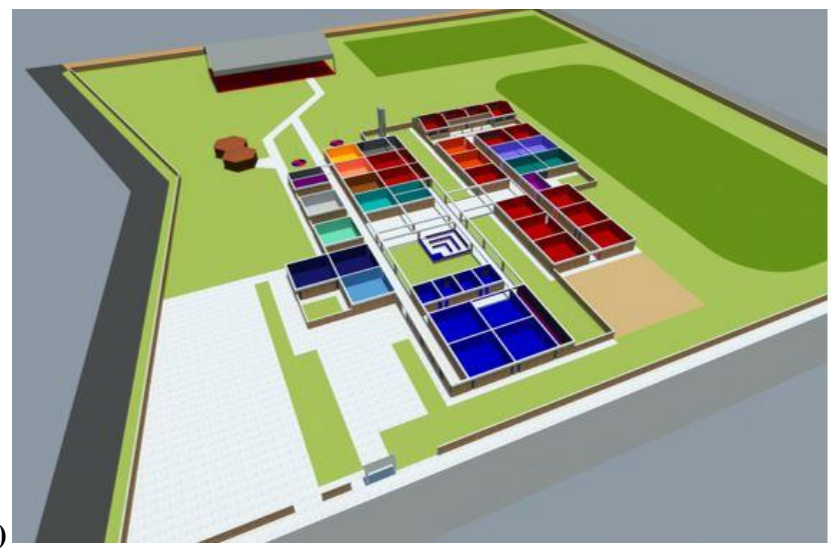

Area administrativa

Área pedagóogica

Cozinha e refeitório

Salas de aula

Sala de dança

Sala de música

Sala de artes

Biblioteca

Laboratórios

Salão de atos

Laboratório de informática

Depósito

Sanitários

Cantina

(b)

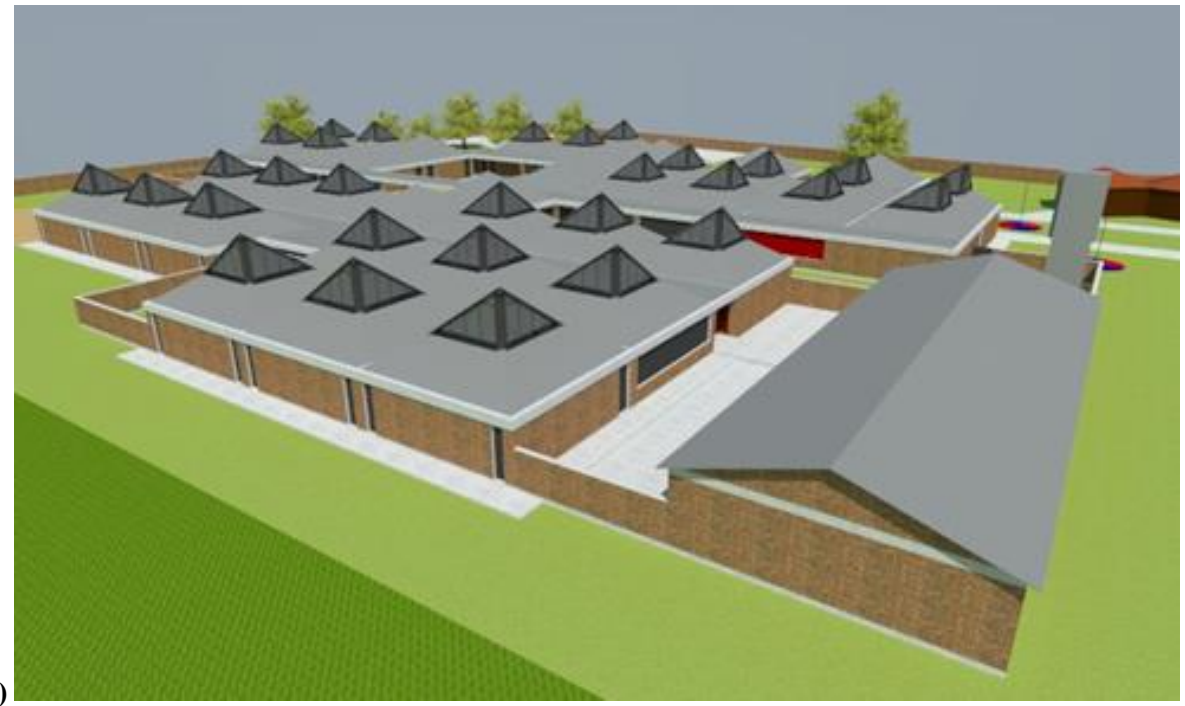

Fonte: elaborado pelos autores (2018)

\section{Considerações Finais}

O desenvolvimento do presente estudo possibilitou a ampliação dos conhecimentos na área educacional, a compreensão espacial e funcional de uma escola, sua relação com o entorno, particularidades do projeto da Escola Estadual Doutor Liberato Salzano Vieira da Cunha dentre outros pormenores associado à responsabilidade do arquiteto dentro da sociedade. Ademais, a pesquisa possibilitou vivência à campo com registros fotográficos, elaboração de croquis, troca de experiências verbais com funcionários do local, além da ampla percepção espacial ao se percorrer o local.

Neste sentido, foram constatadas incoerências projetuais, como na proposta dos sheds - que compõem a maioria dos espaços internos -, paralelamente ao desconforto térmico e lumínico, estes relatados pelos funcionários do local. Em contraponto, é notória a procura de soluções por parte da direção da escola que a anos encontra alternativas - dentro dos recursos viáveis - para atenuar as problemáticas projetuais e revitalizar os espaços a fim de torná-los mais lúdicos e atrativo aos usuários.

Em virtude do que foi mencionado e do processo de análise da escola entende-se a importância do planejamento arquitetônico no cenário escolar e a importância do espaço construído na aprendizagem. 


\section{Referências}

FISCHER, V. L. B. Ambiente escolar, usuários e contexto urbano. In: XI ENTAC Encontro Nacional de Tecnologia no Ambiente Construído: A Construção do Futuro. Anais... Florianópolis, SC: ENTAC, 2006.

GIL, A. C. Como Elaborar Projetos de Pesquisa. 4. ed. São Paulo: Editora Atlas S.A., 2002. ISBN 8522431698.

KOWALTOWSKI, D. C. C. K. Conceitos e Tendências da Arquitetura Escolar. São Paulo, SP: Oficina de Textos, 2011. 272 p. ISBN: 9788579751103.

McDONALD, J. P. Redesigning Schools: Lessons for the 21st Century. The Jossey-Bass Education Series. São Francisco, EUA: ERIC, 1996.

SOPHIA, P. A construção da surpresa. Revista Educação, seção entrevistas/dossiê, setembro de 2011. Disponível em: <http://www.revistaeducacao.com.br/a-construcao-da-surpresa/>. Acesso em 4 abril 2018.

TEIXEIRA, A. Pensamento e ação. Rio de Janeiro, RJ: Civilização Brasileira, 1960.

YIN, R. K. Estudo de caso: planejamento e métodos. 2. ed. Tradução: Daniel Grassi. Porto Alegre, RS: Bookman, 2001. ISBN: 85-7307-852-9. 